\title{
DFT analysis of valproic acid adsorption onto Al12/B12-N12/P12 nanocages with solvent effects
}

Jamelah S Al-Otaibi ( $\sim$ jamelah2019@rediffmail.com )

Princess Nourah bint Abdulrahman University

Y.Sheena Mary

Thushara

\section{Y.Shyma Mary}

Thushara

\section{Research Article}

Keywords: DFT, Valproic acid, solvation, adsorption

Posted Date: January 27th, 2022

DOI: https://doi.org/10.21203/rs.3.rs-1278291/v1

License: (c) (1) This work is licensed under a Creative Commons Attribution 4.0 International License.

Read Full License

Version of Record: A version of this preprint was published at Journal of Molecular Modeling on March 23rd, 2022. See the published version at https://doi.org/10.1007/s00894-022-05088-w. 


\section{Abstract}

Using density functional theory, the adsorption of valproic acid onto the surface of fullerene-like nanocages was investigated. Valproic acid interact the nanocages through the carboxylic group with energies of $-144.14,-109.71,-105.22$ and $-84.96 \mathrm{kcal} / \mathrm{mol}$. The FMOs energy levels were considerably altered upon adsorption, resulting in a reduction in energy gap and increase in electrical conductivity. This suggests that nanocages could be used as sensors as well as options for drug administration in biological systems. Solvation effects in water are also reported.

\section{Introduction}

The impact of nanotechnology on industry and medicine is enormous [1,2]. Many advancement in numerous sectors of research, including microscopic particles and nano-structured materials, have been made in recent years [3-8]. Currently a variety of types have been constructed as possible volunteers for the development of sensors and drug carriers [9-12]. The properties of the drug-nanostructure complex are undergo changes as a result of the electron exchange between the adsorbed molecules and the nanomaterials, which can be monitored as a possible sensor $[6,7,13,14]$. Due to the unique features, particularly the narrow energy gap, fullerenes are one of the most appealing families of nanostructures [13-15]. According to a review of literature, the $\mathrm{Al}_{12} / \mathrm{B}_{12}-\mathrm{N}_{12} / \mathrm{P}_{12}$ structures are the most stable of all the fullerene like structures $[13,14,16,17]$. The medical applications of valproic acid (VLA) and its derivatives are numerous. VLA is a fatty acid that has been used to treat epilepsy, mood disorders, migraines and neuropathic pain [18-21]. Despite its medical benefits, VLA exposure during the pregnancy has been linked to the development of autism [22]. To avoid adverse effects, it is crucial to detect the presence of the VLA in living creatures and give it properly. Due to advantageous physico-chemical features, fullerenes have been studied extensively. Since drug detection has serious ramifications, researchers have looked into targeted drug delivery and sensor applications of fullerenes [23, 24]. Fullerenes have been reported to be employed in the hunt for anticancer medication delivery $[25,26]$. The major goal of the work is to use DFT to investigate possibilities of chemical functionalization of $\mathrm{Al}_{12} / \mathrm{B}_{12^{-}}$ $\mathrm{N}_{12} / \mathrm{P}_{12}$ with VLA. The findings will serve as a foundation for future experimental investigations of drug delivery system development.

\section{DFT calculations}

The Gaussian 16 program suite was used to do all theoretical computations $[27,28]$. Quantum chemistry computations were used to investigate the interaction of VLA with nanocages (NC)with B3LYP/6-311G* basis which is suitable for modeling [29]. To confirm the lowest energy point of all structures, frequency studies were performed in addition to chemical descriptors. The adsorption energy: $E_{a d s}=E_{V L A-N C}-E_{N C}-$ $E_{V L A}$ [30-32] and CPCM model was used to examine solvation effects [33].

\section{Results And Discussion}




\section{Properties of NCs and VLA}

The relaxed ground state structure of VLA and all four NCs, as well as their FMOs distribution and MEP are shown in Figs. 1 and 2. The equilibrium bond length are Al-N =1.7927, 1.8554, Al-P =2.3406, 2.2927, B$\mathrm{N}=1.4385,1.4862$ and $\mathrm{B}-\mathrm{P}=1.9279,1.9047 \AA$ for all pristine cages. The HOMO and LUMO were roughly on the vicinity of $\mathrm{N}, \mathrm{P}$ and $\mathrm{Al}, \mathrm{B}$ atoms, as shown in Fig.2. HOMO and LUMO energies of AIN (AIP) and BN (BP) NCs are -7.1781, -2.5227 (-6.8169, -3.4272) and -7.8594, -1.1050 (-6.9600, -3.2278) eV respectively (table 1). In addition band gaps for AIN (AIP) and BN (BP) NCs are 4.6554 (3.3897) and 6.7544 (3.7322) $\mathrm{eV}$ respectively. Based on Eg values, BN and AIP are the least and the most electrically conductive ones. Using values of Eg, the kinetic stability of the NCs may be examined. The values of relaxed NCs revealed that AIP with low kinetic consistency have more reactivity than the others. The HOMO and LUMO energies for VLA were -7.7222 and -0.4177 eV [34, 35].

Table 1 Chemical descriptors of VLA and NCs

\begin{tabular}{|llllll|}
\hline Property & $\mathrm{VLA}$ & $\mathrm{Al}_{12} \mathrm{~N}_{12}$ & $\mathrm{Al}_{12} \mathrm{P}_{12}$ & $\mathrm{~B}_{12} \mathrm{~N}_{12}$ & $\mathrm{~B}_{12} \mathrm{P}_{12}$ \\
\hline EHOMO $(\mathrm{eV})$ & -7.7222 & -7.1781 & -6.8169 & -7.8594 & -6.9600 \\
\hline ELUMO (eV) & -0.4177 & -2.5227 & -3.4272 & -1.1050 & -3.2278 \\
\hline Eg (eV( & 7.3045 & 4.6554 & 3.3897 & 6.7544 & 3.7322 \\
\hline Fermi level (eV) & -4.0700 & -4.8504 & -5.1221 & -4.4822 & -5.0939 \\
\hline Chemical potential (eV) & -4.0700 & -4.8504 & -5.1221 & -4.4822 & -5.0939 \\
\hline Hardness (eV) & 3.6523 & 2.3277 & 1.6949 & 3.3772 & 1.8661 \\
\hline Softness (1/eV) & 0.1369 & 0.2148 & 0.2950 & 0.1481 & 0.2679 \\
\hline Electrophilicity index (eV) & 2.2677 & 5.0536 & 7.7395 & 2.9744 & 6.9524 \\
\hline DM (Debye) & 1.4902 & 0 & 0 & 0 & 0 \\
\hline Polarizability (a.u.) & 94.7800 & 292.6810 & 613.5573 & 151.9643 & 410.6030 \\
\hline
\end{tabular}

\section{Interaction of VLA and NCs}

The VLA is coupled to surfaces of $\mathrm{Al}_{12} / \mathrm{B}_{12}-\mathrm{N}_{12} / \mathrm{P}_{12}$ via COOH group (Fig.3). The reactive regions of VLA and NCs attached to each other for adsorption process. The values of charges of atoms in VLA interacting with AIN, AIP, BN and BP are $-0.531092,-0.424069,-0.436418,-0.497144(01),-0.330518$, $-0.442946,-0.280203,-0.343344(\mathrm{O} 2), 0.433564,0.469323,0.424040,0.437267(\mathrm{H} 26)$ while that of VLA are $-0.560731,-0384422,0.378393$ e (table 2) [13].

Table 2 Mulliken Charges 


\begin{tabular}{|llllll|}
\hline Atom & VLA & VLA-Al $_{12} \mathrm{~N}_{12}$ & VLA-Al $_{12} \mathrm{P}_{12}$ & VLA-B $_{12} \mathrm{~N}_{12}$ & VLA-B \\
12 & $\mathrm{P}_{12}$ \\
\hline O1 & -0.560731 & -0.531097 & -0.424069 & -0.436418 & -0.497144 \\
\hline O2 & -0.384422 & -0.330518 & -0.442946 & -0.280203 & -0.343344 \\
\hline C3 & -0.275644 & -0.282228 & -0.284642 & -0.286427 & -0.265944 \\
\hline C4 & -0.322307 & -0.399891 & -0.415465 & -0.409100 & -0.405663 \\
\hline C5 & -0.322280 & -0.423527 & -0.415437 & -0.409368 & -0.405191 \\
\hline C6 & -0.341586 & -0.414817 & -0.408842 & -0.403168 & -0.396584 \\
\hline C8 & -0.341591 & -0.399876 & -0.408853 & -0.403102 & -0.397055 \\
\hline C9 & -0.519910 & 0.462745 & 0.512177 & 0.515327 & 0.439798 \\
\hline C10 & -0.518933 & -0.620194 & -0.618319 & -0.616491 & -0.614306 \\
\hline H11 & 0.200684 & 0.229944 & 0.244201 & 0.242565 & 0.226290 \\
\hline H12 & 0.175035 & 0.202266 & 0.217839 & 0.215336 & 0.204066 \\
\hline H13 & 0.189464 & 0.219044 & 0.238217 & 0.230850 & 0.217143 \\
\hline H14 & 0.189481 & 0.214726 & 0.238214 & 0.230841 & 0.216991 \\
\hline H15 & 0.175025 & 0.212242 & 0.217833 & 0.215419 & 0.204001 \\
\hline H16 & 0.180652 & 0.230321 & 0.223462 & 0.212781 & 0.207948 \\
\hline H17 & 0.173591 & 0.196923 & 0.206066 & 0.205727 & 0.200714 \\
\hline H18 & 0.180667 & 0.227612 & 0.223454 & 0.212719 & 0.208131 \\
\hline H19 & 0.173577 & 0.200085 & 0.206063 & 0.205807 & 0.200654 \\
\hline H20 & 0.176851 & 0.209436 & 0.217475 & 0.213320 & 0.206819 \\
\hline H21 & 0.176191 & 0.208677 & 0.215915 & 0.215970 & 0.209171 \\
\hline H22 & 0.171934 & 0.203035 & 0.206508 & 0.206126 & 0.202755 \\
\hline H23 & 0.171928 & 0.203361 & 0.206511 & 0.206147 & 0.202758 \\
\hline H26 & 0.176187 & 0.210058 & 0.215915 & 0.215986 & 0.209184 \\
\hline
\end{tabular}


Table 3 Chemical descriptors in gaseous (water) phase

\begin{tabular}{|c|c|c|c|c|}
\hline Property & VLA-Al ${ }_{12} \mathrm{~N}_{12}$ & VLA-Al ${ }_{12} P_{12}$ & VLA-B ${ }_{12} \mathrm{~N}_{12}$ & VLA-B ${ }_{12} P_{12}$ \\
\hline \multirow[t]{2}{*}{ EHOMO $(\mathrm{eV})$} & -6.1973 & -6.3165 & -7.0262 & -6.9146 \\
\hline & $(-6.2999)$ & $(-6.1546)$ & $(-7.0003)$ & $(-6.5119)$ \\
\hline \multirow[t]{2}{*}{$\operatorname{ELUMO}(\mathrm{eV})$} & -2.5935 & -3.0694 & -1.5698 & -3.2161 \\
\hline & $(-2.2569)$ & $(-2.6433)$ & $(-1.0033)$ & $(-2.7023)$ \\
\hline \multirow[t]{2}{*}{$\mathrm{Eg}(\mathrm{eV})$} & 3.6038 & 3.2471 (3.5113) & $5.4564(5.9970)$ & 3.6985 \\
\hline & $(4.0430)$ & & & $(3.8096)$ \\
\hline \multirow[t]{2}{*}{ Fermi level (eV) } & -4.3954 & -4.6930 & -4.2980 & -5.0654 \\
\hline & $(-4.2784)$ & $(-4.3990)$ & $(-4.0018)$ & $(-4.6071)$ \\
\hline \multirow[t]{2}{*}{ Hardness (eV) } & 1.8019 & $1.6236(1.7557)$ & 2.7282 & 1.8493 (1.9048) \\
\hline & $(2.0215)$ & & $(2.9985)$ & \\
\hline \multirow[t]{2}{*}{ Softness $(1 / \mathrm{eV})$} & 0.2775 & $0.3080(0.2848)$ & 0.1833 & 0.2704 \\
\hline & $(0.2473)$ & & $(0.1668)$ & $(0.2625)$ \\
\hline \multirow{2}{*}{$\begin{array}{l}\text { Chemical potential } \\
(\mathrm{eV})\end{array}$} & -4.3954 & -4.6930 & -4.2980 & -5.0654 \\
\hline & $(-4.2784)$ & $(-4.3990)$ & $(-4.0018)$ & $(-4.6071)$ \\
\hline \multirow{2}{*}{$\begin{array}{l}\text { Electrophilicity } \\
\text { index (eV) }\end{array}$} & 5.3609 & 7.7824 (5.5108) & $3.3855(2.6704)$ & 6.9372 \\
\hline & $(4.5275)$ & & & $(5.5715)$ \\
\hline \multirow[t]{2}{*}{ DM (Debye) } & 2.7098 & $7.2774(9.2743)$ & $6.3482(7.7125)$ & 1.0255 (1.9339) \\
\hline & (3.8107) & & & \\
\hline Polarizability (a.u.) & $\begin{array}{l}390.9723 \\
(580.1210)\end{array}$ & $\begin{array}{l}726.7756 \\
(1409.0643)\end{array}$ & $\begin{array}{l}257.6080 \\
(377.4406)\end{array}$ & $\begin{array}{l}515.5046 \\
(961.5546)\end{array}$ \\
\hline
\end{tabular}

Adsorption of VLA on NCs alters the electronic characteristics of both the nanocages and VLA (tables 1 and 3 ). The electronic and chemical features of nanocages and complexes were investigated using the value of dipole moment (DM). Significant changes in values are detected after the adsorption process. The DM of isolated nanocages was zero due to symmetry, but it increased after adsorption. The DM values in VLA-NCs are varying from 1.0255 (BP-VLA) to 7.2774 (AIP-VLA) Debye. The global reactivity values were crucial for reactivity and stability of VLA, nanocages and nanocages-VLA complexes. Hardness decreased in VLA-NCS, indicating higher reactivity than that of NCs, allowing for more VLA to be adsorbed (tables 1 and 3 ). As a result, the decrease in hardness was followed by an increase in 
softness and chemical potential. Chemical potential for AIN, AIP, BN and BP NCs changed from -4.8504 to $-4.3954,-5.1221$ to $-4.6930,-4.4822$ to -4.2980 and -5.0939 to $-5.0654 \mathrm{eV}$, after adsorption. The highest and the least values of chemical potential shift caused by complexation belong to AIN $(0.4550 \mathrm{eV})$ and $\mathrm{BP}(0.0285 \mathrm{eV})$. The electrophilicity index measures the fragments' capacity to receive electrons [36]. Except for BP, the electrophilicity index increased with VLA adsorption resulting with a higher tendency to accept electrons. The complexes HOMO plots revealed a higher density of electrons around nanocages except AIP while LUMO is over the cages except BN (Fig.4).

Adsorption of VLA onto NCs caused small modifications in FMOs energies. Energies of HOMO, LUMO and Eg for AIN-VLA (AIP-VLA) and BN-VLA (BP-VLA) systems were calculated -6.1973, -2.5935, 3.6038 (and $-6.3165,-3.0694,3.2471)$ and $-7.0262,-1.5698,5.4564(-6.9146,-3.2161,3.6985)$ respectively. Eg values of all nanocage-VLA systems were lowered after adsorption, increases conductivity which is suitable for an electrochemical biosensor for VLA [37, 38].The most reactive sites of VLA (Fig.1) and VLANCs (Fig.5) are identified as favourable charge transfer and interactions in the adsorption process which is supported by the chemical descriptors and Mulliken charge values. The adsorption energies of VLA onto AIN, AIP, BN and BP NCs were calculated $-144.14,-109.71,-105.22$ and $-84.96 \mathrm{kcal} / \mathrm{mol}$ at the optimum distances. The large negative Eads for VLA adsorption suggested a chemisorption .

The DOS plots (Fig.S1) showed how adsorption modifies the electronic characteristics of the nanocages, which may be utilized to estimate their sensitivity to the VLA. The VLA-NCS interaction results in new energy levels near to Fermi level and resulted in low Eg values (Fig.S1). The $\Delta$ Egs are 1.0516, 0.1426, 1.2980 and 0.0337 for complexation of Al/B-N/P. It can be inferred that for the complexation of BN and $\mathrm{BP}$, the maximum and lowest changes in Eg was observed [39,40]. Because Eg is a key element in determining a materials electrical conductivity, the $\mathrm{BN}$ system is expected to produce more changes in conductivity after complexation. A decrease in Eg produces larger electrical conductivity: $\sigma$ a exp($\mathrm{Eg} / 2 \mathrm{KT}$ ) [41]. These findings clearly show that while AIN and AIP are strong adsorbents for VLA, but they are not the greatest options for making a VLA sensor. However, while BN is not the best adsorbent for VLA, it is quite sensitive to it. The findings also suggest that BP is a viable candidate for use as a VLA sensor.

Conjugated structures' thermodynamic properties were also investigated to ensure their thermal stability. Reaction is endothermic/exothermic if $\Delta H>/<0$ and $\Delta G$ tells us whether the VLA and MCs have a spontaneous interaction $(\Delta \mathrm{G}<0)$ or not $(\Delta \mathrm{G}>0)$. The $\Delta \mathrm{G}$ and $\Delta \mathrm{H}$ are given as $[42,43]$ : $\Delta \mathrm{U}=\mathrm{U}_{\mathrm{MC}-\mathrm{VLA}}-\mathrm{U}_{\mathrm{MC}}{ }^{-}$ $U_{V L A}$, where $U$ us the Gibbs free energy $(G)$ and enthalpy $(H)$. In the adsorption behavior of the VLA-MC conjugated structures, VLA interacts with MCs, maintaining distances of 1.7992, 2.8629 ( $O$ to $\mathrm{Al}$ and $\mathrm{O}$ to $\mathrm{N})$ for VLA-AIN, 1.9220, 2.2209 (O to $\mathrm{Al}$ and $\mathrm{OH}$ to $\mathrm{P}$ ) for VLA-AIP, 1.5602, $2.5486(\mathrm{O}$ to $\mathrm{B}$ and $\mathrm{OH}$ to $\mathrm{N}$ ) for VLA-BN and $3.6114,3.8407,2.6434 \AA$ ( $O$ to $P, O H$ to $B$, and $O H$ to $P$ ) for VLA-BP systems. The adsorption energies are highest for all systems except BP-VLA. Furthermore, significant differences in thermodynamic properties were identified for nanocages and the complexes MCs (table 4). The negative values of the above suggest exothermic, spontaneous and thermodynamically ordered interactions. The 
frequencies of all systems are positive, indicating that the examined VLA-MC clusters studied occur naturally [44-48].

Table 4.1. Thermochemical (Thermodynamic) quantities

\begin{tabular}{|c|c|c|c|c|}
\hline Compounds & $\Delta \mathrm{E} /$ Hartree & $\Delta \mathrm{H} /$ Hartree & $\Delta \mathrm{G} /$ Hartree & $\mathrm{S} / \mathrm{cal} / \mathrm{molK}$ \\
\hline VLA & -464.713963 & -464.700517 & -464.754008 & 112.581 \\
\hline $\mathrm{Al}_{12} \mathrm{~N}_{12}$ & -3567.559815 & -3567.538483 & -3567.604394 & 138.720 \\
\hline $\mathrm{Al}_{12} \mathrm{P}_{12}$ & -7006.756850 & -7006.722940 & -7006.816434 & 196.774 \\
\hline $\mathrm{B}_{12} \mathrm{~N}_{12}$ & -956.212430 & -956.201377 & -956.247316 & 96.688 \\
\hline $\mathrm{B}_{12} \mathrm{P}_{12}$ & -4394.912764 & -4394.889848 & -4394.956779 & 140.869 \\
\hline \multicolumn{5}{|c|}{ Gaseous phase } \\
\hline VLA-Al ${ }_{12} \mathrm{~N}_{12}$ & -4032.502568 & -4032.467233 & -4032.567416 & 210.853 \\
\hline VLA-Al ${ }_{12} \mathrm{P}_{12}$ & -7471.643894 & -7471.596248 & -7471.722815 & 266.384 \\
\hline VLA-B ${ }_{12} \mathrm{~N}_{12}$ & -1421.093560 & -1421.069040 & -1421.147595 & 165.333 \\
\hline $\operatorname{VLAB}_{12} \mathrm{P}_{12}$ & -4859.761784 & -4859.723918 & -4859.835292 & 234.407 \\
\hline \multicolumn{5}{|c|}{ Water (solvent) } \\
\hline VLA-Al ${ }_{12} \mathrm{~N}_{12}$ & -4032.561110 & -4032.527040 & -4032.621532 & 198.875 \\
\hline VLA-Al ${ }_{12} \mathrm{P}_{12}$ & -7471.682466 & -7471.637230 & -7471.757034 & 252.149 \\
\hline VLA-B $_{12} \mathrm{~N}_{12}$ & -1421.123953 & -1421.100070 & -1421.175654 & 159.080 \\
\hline $\operatorname{VLAB}_{12} \mathrm{P}_{12}$ & -4859.783702 & -4859.747681 & -4859.849936 & 215.214 \\
\hline
\end{tabular}

Table 4.2. Changes of the thermochemical quantities 


\begin{tabular}{|c|c|c|c|c|}
\hline Compounds & $\Delta \mathrm{E} / \mathrm{kcal} / \mathrm{mol}$ & $\Delta \mathrm{H} / \mathrm{kcal} / \mathrm{mol}$ & $\Delta \mathrm{G} / \mathrm{kcal} / \mathrm{mol}$ & $\mathrm{S} / \mathrm{cal} / \mathrm{molK}$ \\
\hline \multicolumn{5}{|c|}{ Gaseous phase } \\
\hline VLA-Al ${ }_{12} \mathrm{~N}_{12}$ & -143.57 & -143.22 & -131.16 & -40.448 \\
\hline VLA-Al ${ }_{12} \mathrm{P}_{12}$ & -108.61 & -108.43 & -95.62 & -42.971 \\
\hline VLA-B ${ }_{12} \mathrm{~N}_{12}$ & -104.90 & -104.89 & -91.79 & -43.936 \\
\hline $\mathrm{VLAB}_{12} \mathrm{P}_{12}$ & -84.75 & -83.81 & -78.13 & -19.043 \\
\hline \multicolumn{5}{|c|}{ Water (solvent) } \\
\hline VLA-Al ${ }_{12} \mathrm{~N}_{12}$ & -180.30 & -180.75 & -165.12 & -52.426 \\
\hline VLA-Al ${ }_{12} \mathrm{P}_{12}$ & -132.81 & -134.14 & -117.09 & -57.206 \\
\hline VLA-B ${ }_{12} \mathrm{~N}_{12}$ & -123.97 & -124.36 & -109.39 & -50.189 \\
\hline $\operatorname{VLAB}_{12} \mathrm{P}_{12}$ & -98.50 & -98.72 & -87.32 & -38.236 \\
\hline
\end{tabular}

\section{Solvation energies}

In solution phase, the total energy values of nanocage-VLA are higher than that in the gaseous phase. This shows that the examined complex's stability if higher in the solution phase than in the gas phase. The solvation energy SFE $=E_{\text {solvent }}-E_{\text {gas }}$. The solvation energies are $-179.23,-131.66,-122.48$ and -98.00 $\mathrm{kcal} / \mathrm{mol}$ for Al/B-N/P with VLA systems. For all systems in solvent water, the thermodynamic parameter changes are negative showing the processes as spontaneous and exothermic (table 4). In solution phase, the DM values (table 3) of the complex increase, which is due to long range interactions of the solvent with the solute molecule. In solution phase, the complex's polarizability values are higher and the stability of HOMO and LUMO rises and the high energy gap indicate that energy is transferred efficiently between them. The Eg value in solution phase increases as compared to the gaseous phase which reveal that the nanocages are is set to share electrons (table 3). The $\triangle \mathrm{Eg}$ of VLA-MCs conjugated structures in solvents was also calculated as $0.6124 / 0.1216 / 0.7574 / 0.0774$ for VLA-AIN/AIP/BN/BP and discussed in order to nominate an electrical sensor for the VLA. In VLA-MCs clusters energy gap increases in all solvents. It means the nanocages are good sensors as supported by its solvation or adsorption energies. This is also evident from the Raman spectra (Fig.S2) in which in the finger print regions maximum enhancements are for VLA-MCs clusters due to SERS effects $[44,49]$. Most of the modes are enhanced in complexes due to the interaction between VLA and nanocages.

\section{Conclusion}

DFT computations were used to study adsorption of valproic acid on Al/B-N/P nanocages. The chemical descriptors and electronic features are modified due to the adsorption process. The drug was attached to 
the nanocages via the $\mathrm{COOH}$ groups' oxygen and hydrogen atoms with reasonable adsorption energies. The exothermic nature of process was demonstrated by negative adsorption energies and thermodynamic parameters. The adsorption energies are $-144.14,-109.71,-105.22,-84.96$ and the solvation energies in water are $-179.23,-131.66,-122.48$ and $-98.00 \mathrm{kcal} / \mathrm{mol}$ for VLA in Al/B-N/P nanocages. Most reactive sites are identified which are suitable for adsorption and charge transfer.

\section{Declarations}

\section{Acknowledgments}

The authors express their gratitude to Princess Nourah bint Abdulrahman University Researchers Supporting Project number (PNURSP2022R13), Princess Nourah bint Abdulrahman University, Riyadh, Saudi Arabia

\section{Author contribution}

Jamelah S.Al-Otaibi: Software, Supervision, manuscript preparation and data analysis

Y.Sheena Mary: Supervision, manuscript preparation, conceiving the problem and data analysis

Y.Shyma Mary: Manuscript preparation, conceiving the problem and data analysis and correction

Data availability: The supplementary information files include additional materials

Code availability: No new codes have been created. Existing codes were utilized and quoted correctly

Conflict of interest The authors declare no competing interests

\section{References}

1. J.Beheshtian, A.A.Peyghan, M.Noei, Sensing behavior of Al and Si doped BC3 graphenes to formaldehyde, Sensors and Actuators B: Chemical 181 (2013) 829-834. https://doi.org/10.1016/j.snb.2013.02.086

2. A.S.Rad, V.Samipour, S.Movaghgharnnezhad, A.Mirabi, M.H.Shahavi, B.K.Moghadas, X12N12 $(\mathrm{X}=\mathrm{Al}, \mathrm{B})$ cluster for protection of vitamin C: molecular modeling investigation, Surface and Interfaces 15 (2019) 30-37. https://doi.org/10.1016/j.surfin.2019.02.001

3. A.H.Almuqrin, J.S.Al-Otaibi, Y.S.Mary, Y.S.Mary, R.Thomas, Structural study of letrozole and metronidazole and formation of self assembly with graphene and fullerene with the enhancement of physical, chemical and biological activities, Journal of Biomolecular Structure and Dynamics, 39 (2021) 5509-5515. https://doi.org/10.1080/07391102.2020.1790420

4. J.S.Al-Otaibi, Y.S.Mary, R.Thomas, S.Kaya, Detailed electronic structure, physico-chemical properties, excited state properties, virtual bioactivity screening and SERS analysis of three guanine based 
antiviral drugs, valacyclovir $\mathrm{HCl}$ hydrate, Acyclovir and ganciclovir, Polycyclic Aromatic Compounds (2020). https://doi.org/10.1080/10406638.2020.1773876

5. J.S.Al-Otaibi, Y.S.Mary, Y.S.Mary, S.Kaya, S.Erkan, Spectral analysis and DFT investigation of some benzopyran analogues and their self assemblies with graphene, Journal of Molecular Liquids 317 (2020) 113924. https://doi.org/10.1016/j.molliq.2020.113924

6. A.S.Rad, K.Ayub, Adsorption properties of acetylene and ethylene molecules onto pristine and nickel decoarated Al12N12 nanoclsuters, Materials Chemistry and Physics 194 (2017) 337-344. https://doi.org/10.1016/j.matchemphys.2017.04.002

7. A.S.Rad, K.Ayub, DFT study of boron trichloride adsorption on the surface of Al12N12 nanocluster, Molecular Physics 115 (2017) 879-884. https://doi.org/10.1080/00268976.2017.1290843

8. S.P.Velammal, T.A.Devi, T.P.Amaladhas, Antioxidant, antimicrobial and cytotoxic activities of silver and gold nanoparticle ssynthesized using plumbago zylanica bark, Journal of Nanostructure in Chemistry, 6 (2016) 247-260. https://doi.org/10.1007/s40097-016-0198-x

9. Z.Goodarzi, M.Maghrebi, A.F.Zavareh, Z.B.Mokhtari-Hosseini, B.Ebrahimi-Hoseinzadeh, A.H.Zarmi, M.Barshan-Tashnizi, Evaluation of nicotine sensor based on copper nanoparticles and carbon nanotubes, Journal of Nanostructure in Chemistry, 5 (2015) 237-242. https://doi.org/10.1007/s40097-015-0154-1

10. K.Harismah, M.Mirzaei, M.Samadizadeh, A.S.Rad, DFT studies of stabilities and properties for X3Y6Z9 borazine like structures (X=B/Al, Y-N/P, Z=H/Me), Superlattices and Microstructures 109 (2017) 360-365. https://doi.org/10.1016/j.spmi.2017.05.027

11. Z.Jafari, R.Baharfar, A.S.Rad, S.Asghari, Potential of graphene oxide as a drug delivery system for sumatriptan: a detailed density functional theory study, Journal of Biomolecular Structure and Dynamics (2020). https://doi.org/10.1080/07391102.2020.1736161

12. B.Khodashenas, M.Ardjmand, S.B.Mazyar, A.S.Rad, A.A.Khiyavi, Bovine serum albumin/gold nanoparticles as a drug delivery system for curcumin: experimental an dcomputational studies, Journla of Biomolecular Structure and Dynamics (2019). https://doi.org/10.1080/07391102.2019.1683073

13. R.Padash, M.Rahimi-Nasrabadi, A.S.Rad, A.Sobhani-Nasab, T.Jesionowski, H.Ehrlich, A comparative computational investigation of phosgene adsorption on $(X Y) 12(X=A l, B$ and $Y=N, P)$ nanoclusters: DFT investigations, Journal of Cluster Science 30 (2019) 203-218. https://doi.org/10.1007/s10876018-1479-y

14. R.Padash, A.Sobhani-Nasab, M.Rahimi-Nasrabadi, M.Mirmotahri, H.Enrlich, A.S.RAd, M.Peyravi, Is it possible to use $\mathrm{X} 12 \mathrm{Y} 12(\mathrm{X}=\mathrm{Al}, \mathrm{B}$ and $\mathrm{Y}=\mathrm{N}, \mathrm{P})$ nanocages for drug delivery systems? A DFT study on the adsorption property of 4-aminopyriidne drug, Applied Physics A 124 (2018) 582. https://doi.org/10.1007/s00339-018-1965-y

15. M.Sherfati, A.S.Rad, M.Ardjmand, A.Heydarinasab, M.Peyravi, M.Mirzaei, Beryllium oxide (BeO) nanotube provides excellent surface towards adenine adsorption: A dispersion-corrected DFT study 
in gas and water phases, Current Applied Physics 18 (2018) 1059-1065. https://doi.org/10.1016/j.cap.2018.05.024

16. D.L.Strout, Structure and stability of boron nitrides: isomers of B12N12, The Journal of Physical Chemistry A 104 (2000) 3364-3366. https://doi.org/10.1021/jp994129a

17. R.Wang, D.Zhang, C.Liu, Theoretical prediction of a novel inorganic fullerene like family of silicon carbon materials, Chemical Physiscs letters 411 (2005) 333-338.

https://doi.org/10.1016/j.cplett.2005.06.055

18. W.Loscher, Basic pharmacology of valproate: a review after 35 years of clinical use for the treatment of epilepsy, CNS Drugs 16 (2002) 669-694. https://doi.org/10.2165/00023210-200216100-00003

19. A.M.Waszkielewicz, A.Gunia, K.Sloczynska, H.Marona, Evaluation of anticonvulsants for possible use in neuropathic pain, Curr. Med. Chem. 18 (2011) 4344-4358.

https://doi.org/10.2174/092986711797200408

20. C.T.Chiu, Z.Wang, J.G.Hunsberger, D.M.Chuang, Therapeutic potential of mood stabilizers lithium and valproic acid: beyond bipolar disorder, Pharmacol. Rev. 65 (2013) 105-142. https://doi.org/10.1124/pr.111.005512

21. J.Hoffmann, S.Akerman, P.J.Goadsby, Efficacy and mechanism of anticonvulsant drugs in migraine, Expert Rev. Clin. Pharmacol. 7 (2014) 191-201. https://doi.org/10.1586/17512433.2014.885835

22. A.Ornoy, Valproic acid in pregnancy: how much are we endangering the embryo and fetus? Reprod. Toxicol. 28 (2009) 1-10. https://doi.org/10.1016/j.reprotox.2009.02.014

23. T.Da Ros, Twenty years of promises: Fullerene in medicinal chemistry: in: F.Cata,dp. T.Da Ros (eds), Medicinal chemistry and pharmacological potential of fullerenes and carbon nanotubes, Carbon Materials: Chemistry and Physics, vol.1, Springer, Dordrecht, https://doi.org/10.1007/978-1-40206845-4_1

24. R.Singh, J.W.Lillard, Nanoparticle based targeted drug delivery, Exp. Mol. Pathol. 86 (2009) 215-223. https://doi.org/10.1016/j.yexmp.2008.12.004

25. T.Y.Zakharian, A.Seryshev, B.Sithraman, B.E.Gilbert, V.Knight, L.J.Wilson, A fullerene paclitaxel chemotherapeutic: synthesis, characterization and study of biological activity in tissue culture, J. Am. Chem. Soc. 127 (2005) 12508-12509. https://doi.org/10.1021/ja0546525

26. J.M.Ashcroft, D.A.Tsyboulski, K.B.Hartman, T.Y.Zakharian, J.W.Marks, R.B.Weisman, M.G.Rosenblum, L.J.Wilson, Fullerene (C60) immunoconjugates: interaction of water soluble $\mathrm{C} 60$ derivatives with the murine anti-gp240 melanoma antibody, Chem. Commun. (Camb) 28 (2006) 3004-3006. https://doi.org/10.1039/B601717G

27. Gaussian 16, Revision A.03, M.J. Frisch, G.W. Trucks, H.B. Schlegel, G.E. Scuseria, M.A. Robb, J.R. Cheeseman, G. Scalmani, V. Barone, G.A. Petersson, H. Nakatsuji, X. Li, M. Caricato, A.V. Marenich, J. Bloino, B.G. Janesko, R. Gomperts, B. Mennucci, H.P. Hratchian, J.V. Ortiz, A.F. Izmaylov, J.L. Sonnenberg, D. Williams-Young, F. Ding, F. Lipparini, F. Egidi, J. Goings, B. Peng, A. Petrone, T. Henderson, D. Ranasinghe, V.G. Zakrzewski, J. Gao, N. Rega, G. Zheng, W. Liang, M. Hada, M. Ehara, K. Toyota, R. Fukuda, J. Hasegawa, M. Ishida, T. Nakajima, Y. Honda, O. Kitao, H. Nakai, T. Vreven, K. 
Throssell, J.A. Montgomery, Jr., J.E. Peralta, F. Ogliaro, M.J. Bearpark, J.J. Heyd, E.N. Brothers, K.N. Kudin, V.N. Staroverov, T.A. Keith, R. Kobayashi, J. Normand, K. Raghavachari, A.P. Rendell, J.C. Burant, S.S. Iyengar, J. Tomasi, M. Cossi, J.M. Millam, M. Klene, C. Adamo, R. Cammi, J.W. Ochterski, R.L. Martin, K. Morokuma, O. Farkas, J.B. Foresman, and D. J. Fox, Gaussian, Inc., Wallingford CT, 2016.

28. GaussView, Version 6.1, R.Dennington, T.A.Keith, J.M.Millam, Semichem Inc., Shawnee Mission, KS, 2016.

29. K.Mahboobeh, T.L.Elham, B12Y12 (Y:N,P) fullerene like cages for emestane-delivery, molecular modeling investigation, J. Mol. Struct. 1217 ( 2020) 128455.

https://doi.org/10.1016/j.molstruc.2020.128455

30. R.Padash, M.R.Esfahani, A.S.Rad, The computational quantum mechanical study of sulfamide drug adsorption ontoX12Y12 fullerene like nanocages: detailed DFT and QTAIM investigations, Journal of Biomolecular Structure and Dynamics (). https://doi.org/10.1080/07391102.2020.1292991

31. Y.S.Mary, VS.Kumar, Y.S.Mary, K.S.Resmi, R.Thomas, Detailed quantum mechanical studies on three bioactive benzimidazole derivatives and their Raman enhancement on adsorption over graphene sheets, Polycyclic Aromatic Compounds (2020). https://doi.org/10.1080/10406638.2020.1852267

32. J.S.Al-Otaibi, A.H.Almuqrin, Y.S.Mary, Y.S.Mary, Utilization of O/S-doped graphene nanoclusters for ultrasensitive detection of flurane derivatives-DFT investigations, Journal of Biomolecular Structure and Dynamics (2020). https://doi.org/10.1080/07391102.2020.1870155

33. M.Cossi, N.Rega, G.Scalmani, V.Barone, Energies, structures, and electronic properties of molecules in solution with the C-PCM solvation model, J. Comp. Chem. 24 (2003) 669-681. https://doi.org/10.1002/jcc.10189

34. A.H.Almuqrin, J.S.Al-Otaibi, Y.S. Mary, R.Thomas, S.Kaya, DO.Isin, Spectral analysis and detailed quantum mechanical investigation of some acetanilide analogues and their self assemblies with graphene and fullerene, Journal of Molecular Modeling 26 (2020) 254. https://doi.org/10.1007/s00894-020-04485-3

35. J.S.Al-Otaibi, A.H.Almuqrin, Y.S.Mary, Y.S.Mary, C.Van Alsenoy, DFT and molecular docking studies of self-assembly of sulfone analogues and graphene, Journal of Molecular Modeling 26 (2020) 273. https://doi.org/10.1007/s00894-020-04546-7

36. N.M.O'boyle, A.L.Tenderholt, K.M.Langner, CClib: a library for package independent computational chemistry algorithms, Journal of Computational Chemistry 29 (2008) 839-845. https://doi.org/10.1002/jcc.20823

37. J.S.Al-Otaibi, A.H.Almuqrin, Y.S.Mary, Y.S.Mary, R.Thomas, Modeling the conformational preference, spectral analysis and other quantum mechanical studies on three bioactive aminobenzoate derivatives and their SERS active graphene complexes, Polycyclic Aromatic Compounds (2020). https://doi.org/10.1080/10406638.2020.1827270

38. Y.S.Mary, Y.S.Mary, S.Armakovic, S.J.Armakovic, B.Narayana, Understanding reactivity of a triazole derivative and its interaction with graphene and doped/undoped coronene- a DFT study, , Journal of 
Biomolecular Structure and Dynamics (2020). https://doi/org/10.1080/07391102.2020.1837677

39. A.H.Almuqrin, J.S.Al-Otaibi, Y.S.Mary, Y.S.Mary, DFT computational study towards investigating psychotropic drugs, promazine and trifluoperazine adsorption on graphene, fullerene and carbon cyclic ring nano clusters, Spectrochim. Acta 246 (2021) 119012. https://doi.org/10.1017/j.saa.2020.119012

40. J.S.Al-Otaibi, Y.S.Mary, Y.S.Mary, G.Serdaroglu, Adsorption of adipic acid in Al/B-N/P nanocages: DFT investigations, Journal of Molecular Modeling, 27 (2021) 113. https://doi.org/10.1007/s00894-02104742-z

41. J.S.Al-Otaibi, Y.S.Mary, Y.S.Mary, S.Kaya, G.Serdaroglu, DFT computational study of trihalogenated aniline derivative's adsorption onto graphene/ fullerene/fullerene-like nanocages, $\mathrm{X} 12 \mathrm{Y} 12$ (X=Al, B and $\mathrm{Y}=\mathrm{N}, \mathrm{P})$, Journal of Biomolecular Structure and Dynamics (2020). https://doi.org/10.1080/07391102.2021.1914172

42. A.S.Rad, First principles study of Al-doped graphene as nanostructure adsorbent for NO2 and N2O: DFT calculations, Appl. Surf. Sci. 357 (2015) 1217-1224. https://doi.org/10.1016/j.apsusc.2015.09.168

43. M.Zou, J.Zhang, J.Chen, X.Li, Simulating adsorption of organic pollutants on finite $(8,0)$ single walled carbon nanotubes in water, Environ. Sci. Technol. 46 (2012) 8887-8894. https://doi.org/10.1021/es301370f

44. J.S.Al-Otaibi, Y.S.Mary, Y.S.Mary, Adsorption of a thione bioactive derivative over different silver/gold clusters - DFT investigations, Computational and Theoretical Chemistry 1207 (2022) 113497. https://doi.org/10.1016/j.comptc.2021.113497

45. J.S.Al-Otaibi, Y.S.Mary, Y.S.Mary, Z.Ullah, R.Yadav, N.Gupta, D.G.Churchill, Adsorption properties of dacarbazine with graphene/fullerene/metal nanocages-reactivity, spectroscopic and SERS analysis, Spectrochim. Acta (2021) 120677. https://doi.org/10.1016/j.saa.2021.120677

46. Y.S.Mary, Y.S. Mary, Z. Ullah, Computational study of sorbic acid drug adsorption onto coronene/fullerene/fullerene-like $\mathrm{X} 12 \mathrm{Y} 12$ ( $\mathrm{X}=\mathrm{Al}, \mathrm{B}$ and $\mathrm{Y}=\mathrm{N}, \mathrm{P})$ nanocages: DFT and molecular docking investigations, Journal of Cluster Science (2021). https://doi.org/10.1007/s10876-02102106-4

47. J.S.Al-Otaibi, Y.S.Mary, Y.S.Mary, R.Thomas, Evidence of cluster formation of croconic acid with Ag, $\mathrm{Au}$ and $\mathrm{Cu}$ cages, enhancement of electronic properties and Raman activity, Spectrochim. Acta 264 (2022) 120233. https://doi.org/10.1016/j.saa.2021.120233

48. J.S.Al-Otaibi, Y.S.Mary, Y.S.Mary, R.Trivedi, B.Chakraborty, Theoretical investigation on the adsorption of melamine in Al12/B12-N12/P12 fullerene-like nanocages: a platform for ultrasensitive detection of melamine, Chemical Papers (2021). https://doi.org/10.1007/s11696-021-01849-8

49. J.S.Al-Otaibi, Y.S.Mary, Y.S.Mary, Z.Ullah, H.W.Kwon, Adsorption behavior and solvent effects of an adamantane-triazole derivative on metal clusters-DFT simulation studies, Journal of Molecular Liquids 345 (2022) 118242. https://doi.org/10.1016/j.molliq.2021.118242. 
Figures

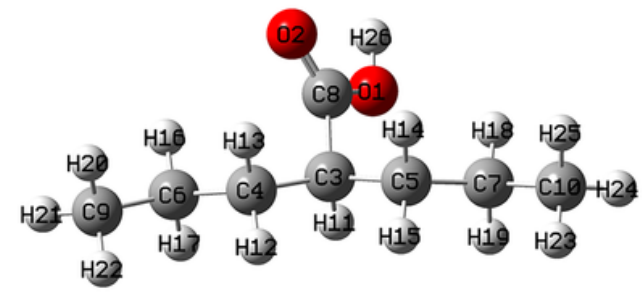

(a)

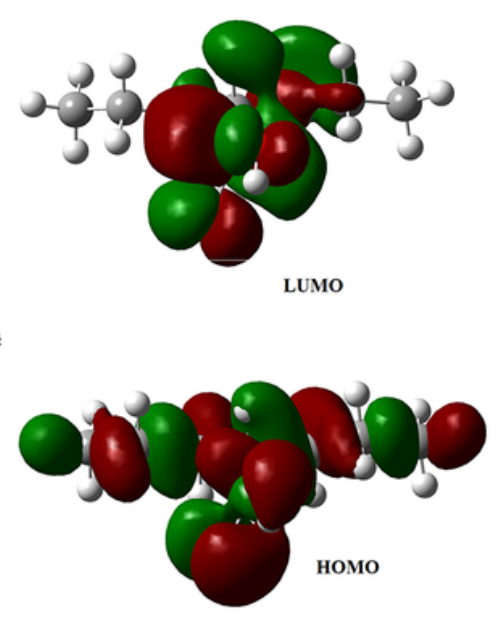

(b)

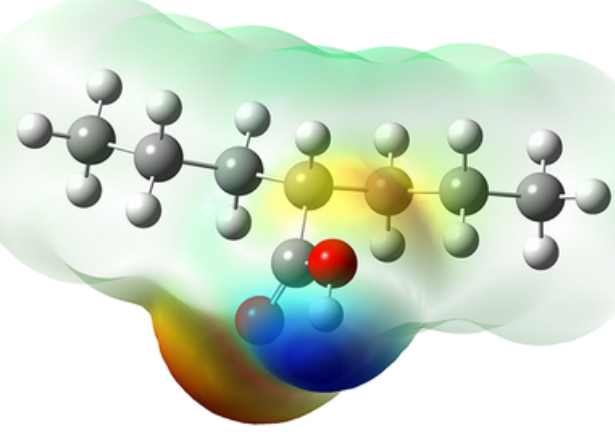

(c)

Figure 1

(a) Optimized geometry of VLA (b) FMO plots (c) MEP plot 


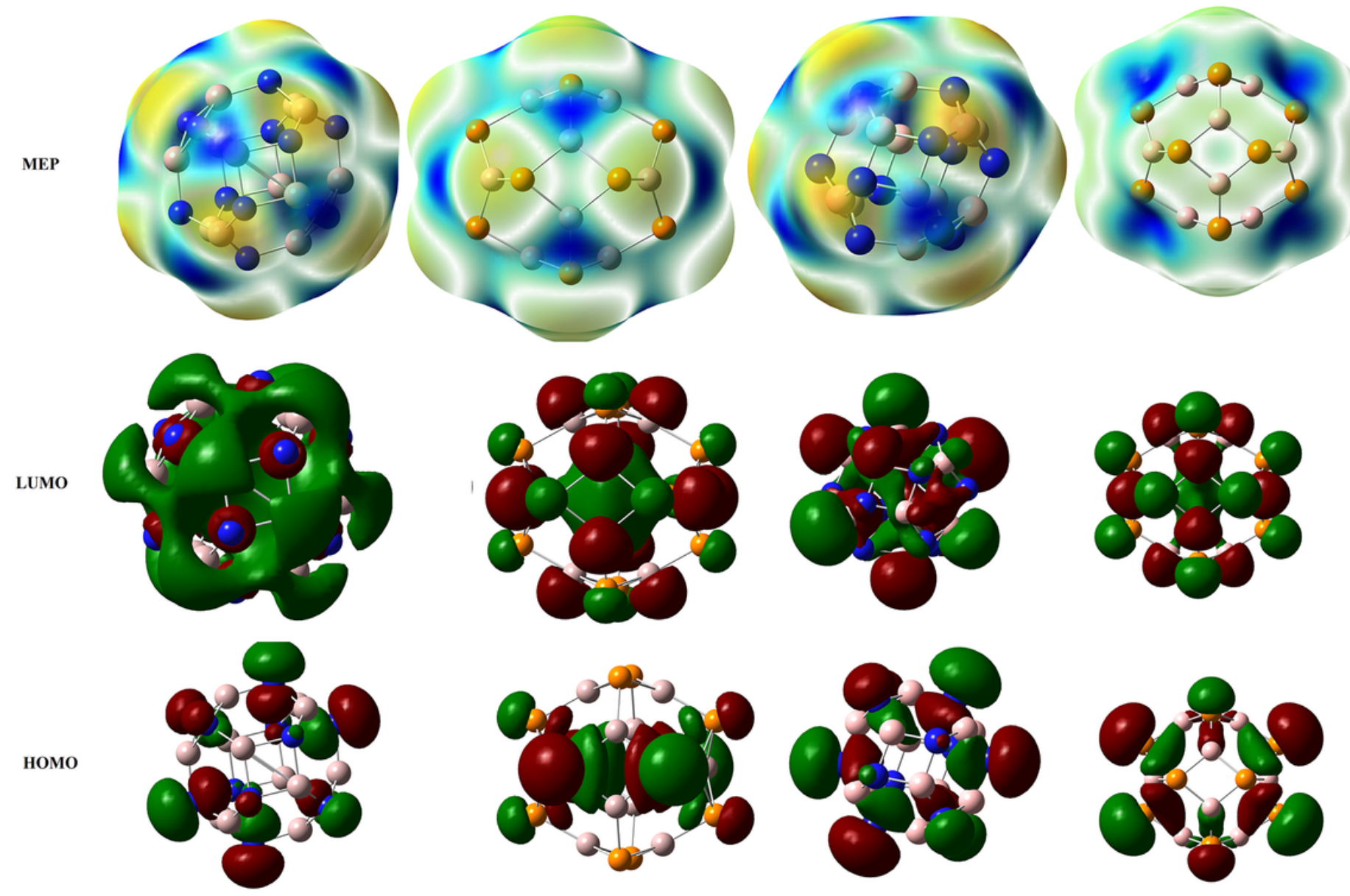

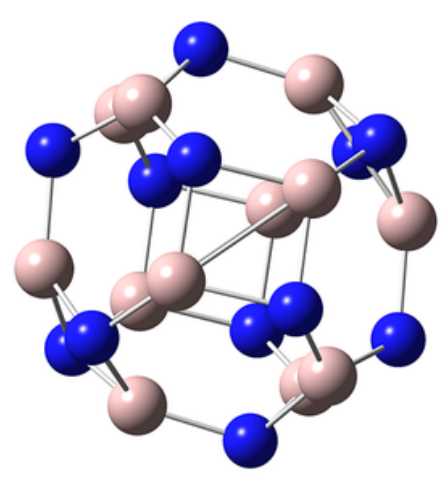

(a)

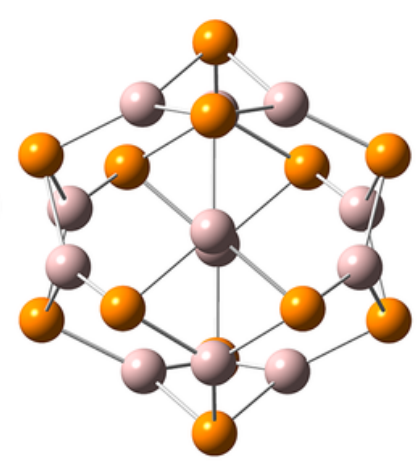

(b)

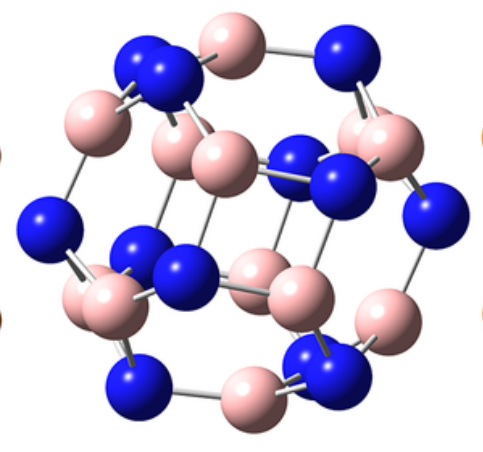

(c)

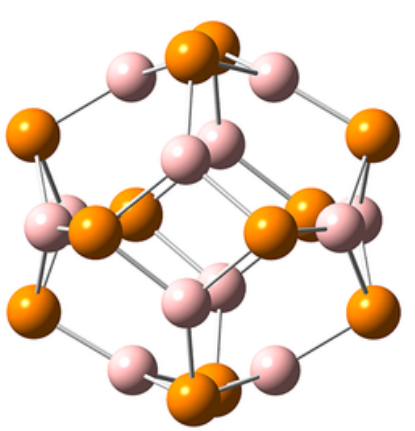

(d)

Figure 2

Optimized geometries, FMO plots and MEP plots of (a)Al12N12 (b) Al12P12 (c) B12N12 (d) B12P12 


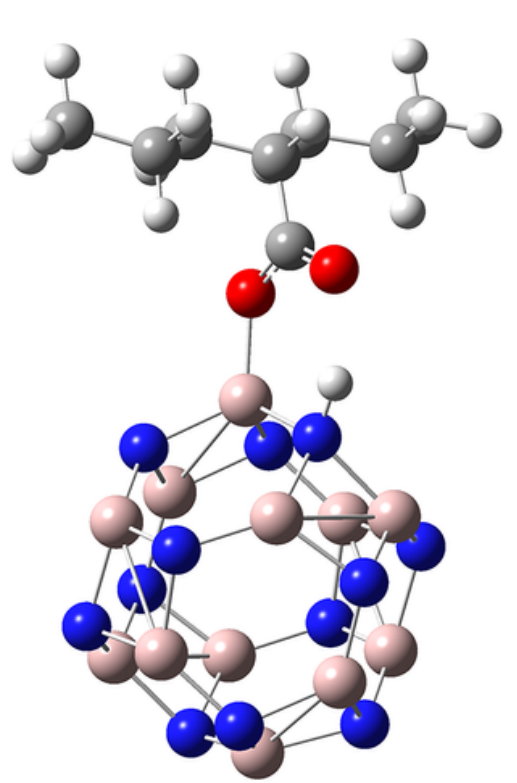

(a)

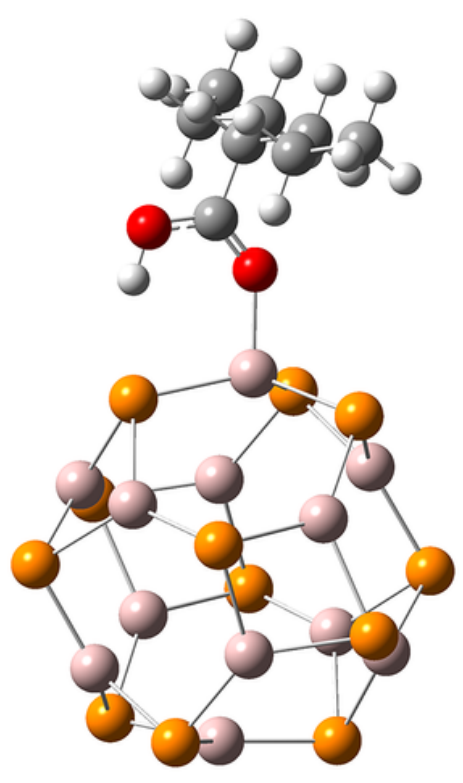

(b)

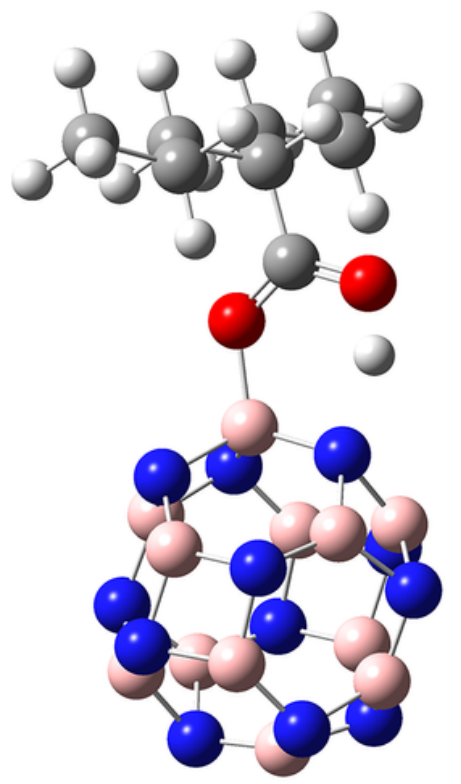

(c)
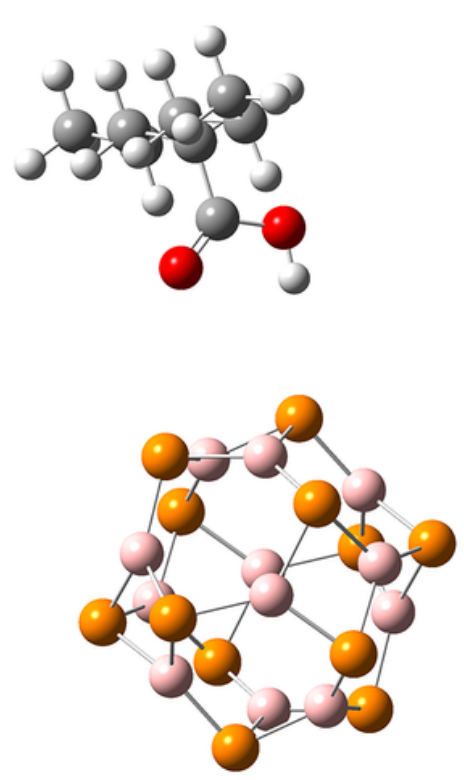

(d)

Figure 3

Optimized geometries of (a) VLA-Al12N12 (b) VLA-Al12P12 (c) VLA-B12N12 (d) VLA-B12P12 


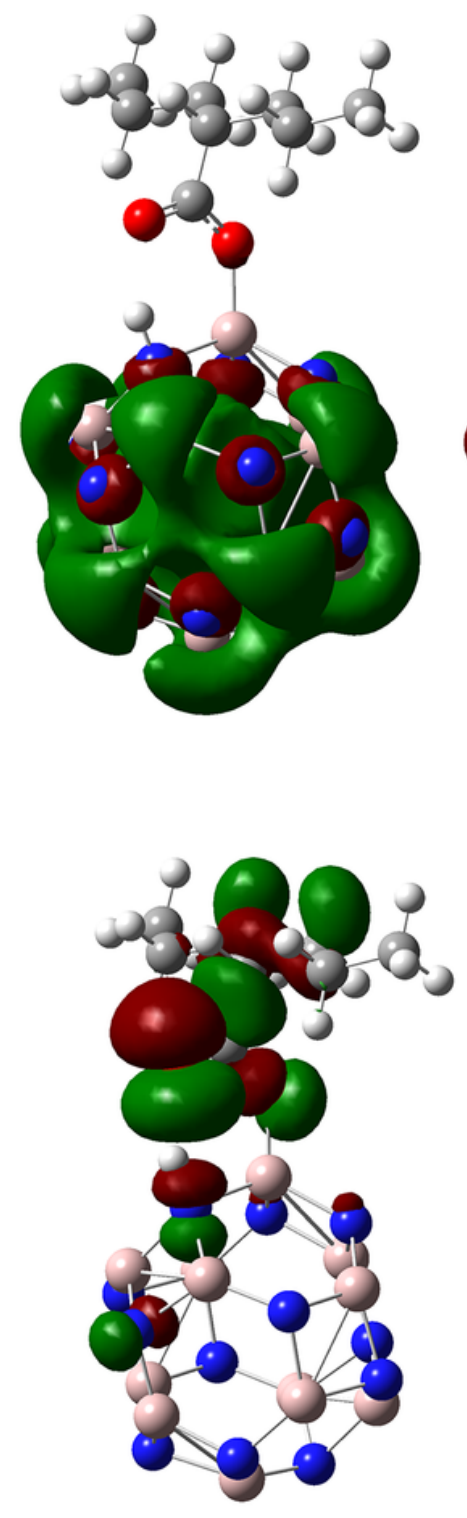

(a)
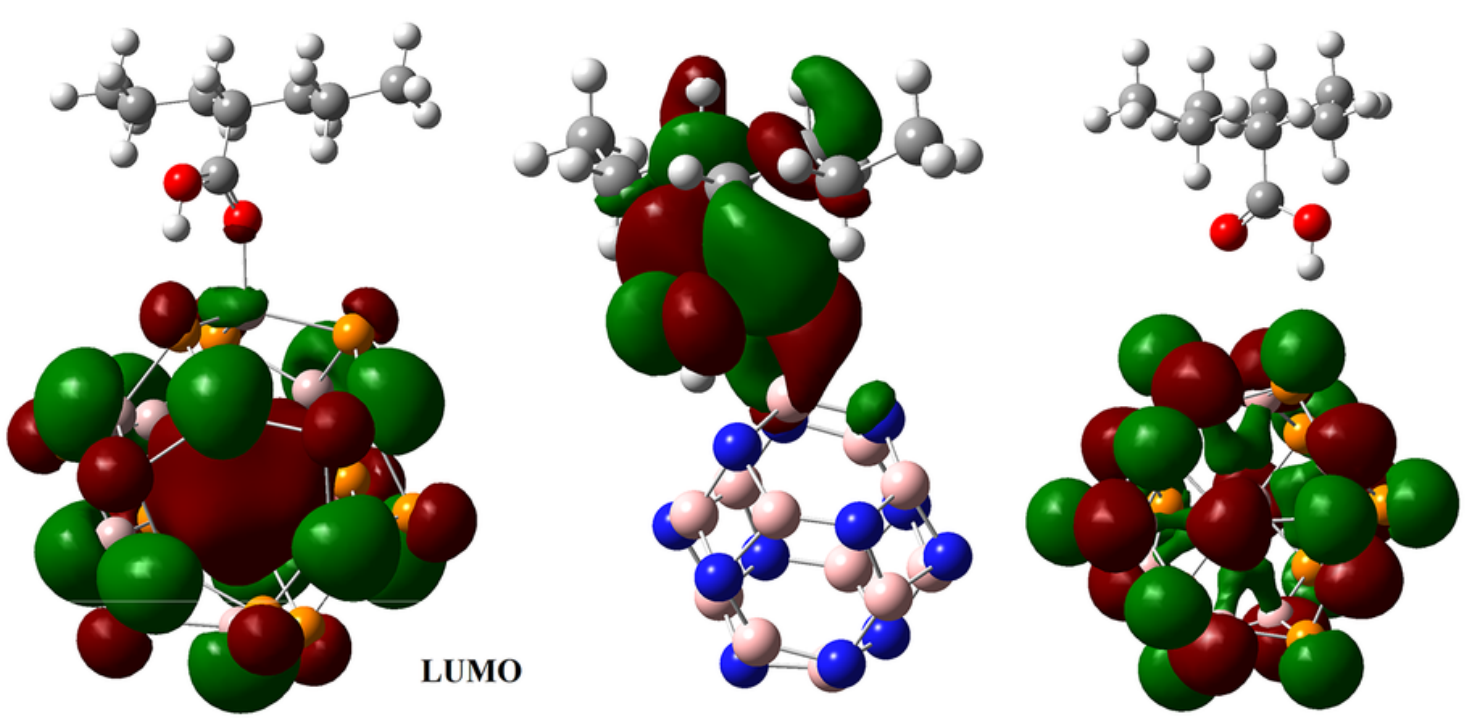

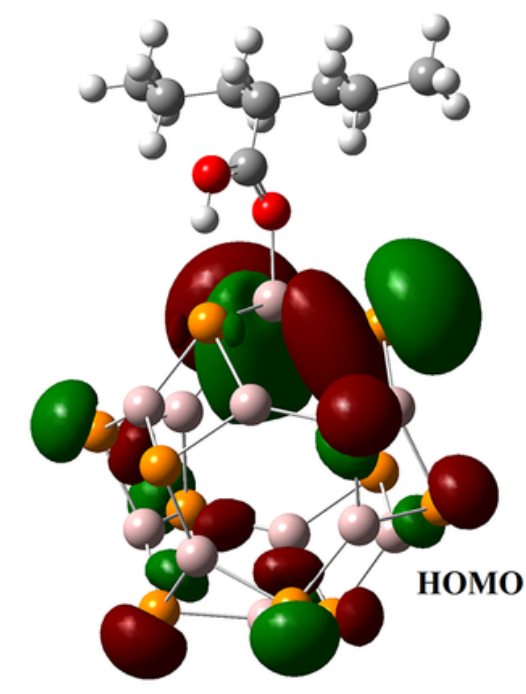

(b)

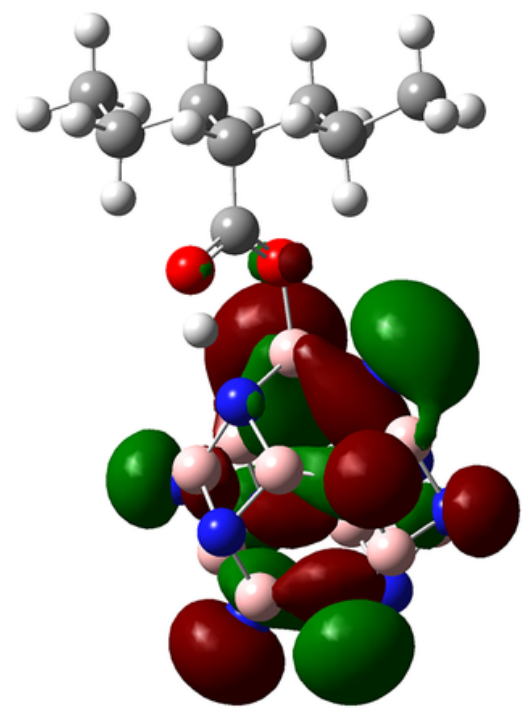

(c)

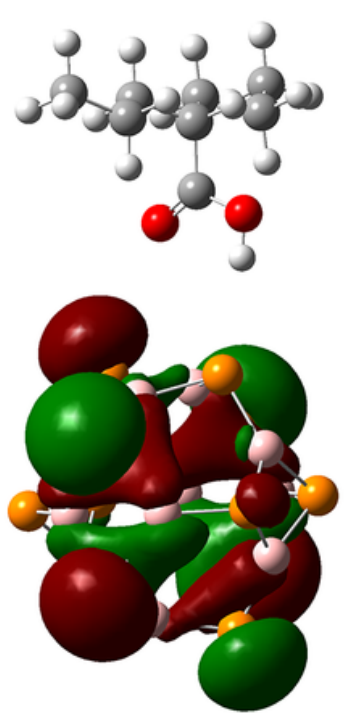

(d)

Figure 4

HOMO-LUMO plots of (a) VLA-Al12N12 (b) VLA-Al12P12 (c) VLA-B12N12 (d) VLA-B12P12 


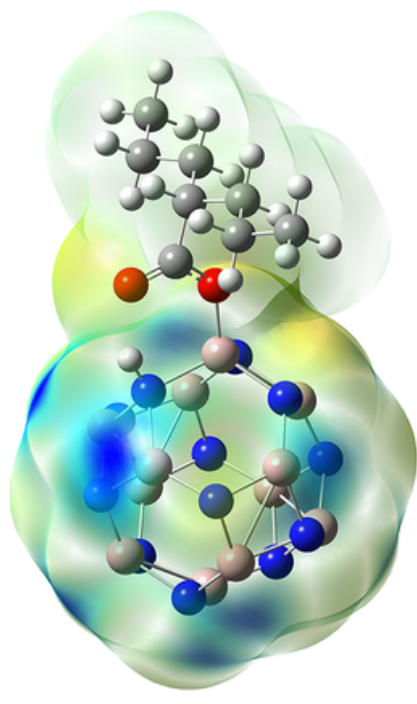

(a)

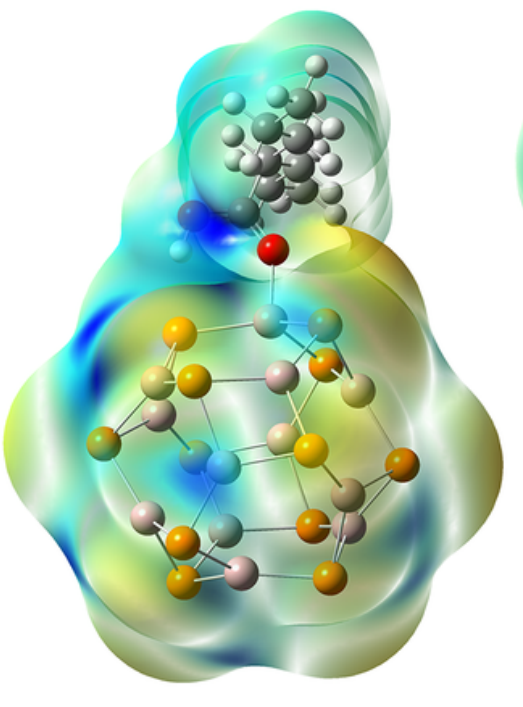

(b)

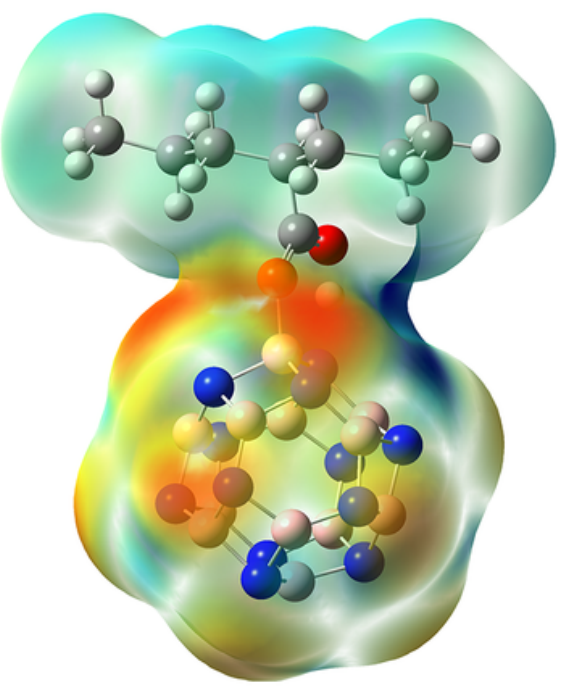

(c)

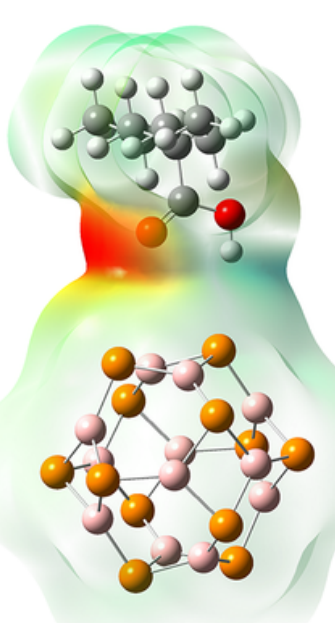

(d)

Figure 5

MEP plots of (a) VLA-Al12N12 (b) VLA-Al12P12 (c) VLA-B12N12 (d) VLA-B12P12

\section{Supplementary Files}

This is a list of supplementary files associated with this preprint. Click to download.

- graphicalabstract.docx

- valsupport.docx 